\title{
EVALUATION OF RESORBABLE MESH AND PLATE WITH ULTRASONIC WELDED PINS IN THE MANAGEMENT OF MANDIBULAR FRACTURES IN CHILDREN (A COMPARATIVE CLINICAL STUDY)
}

Marwa G. Noureldin ${ }^{l} M s c$, Abdelaziz F. Khalil ${ }^{2} P h D$, Ahmed R. Kotb ${ }^{2} P h D$, Magued H. Fahmy $2 h D$, Salah Eldin D. Abo Eleneen ${ }^{3} P h D$

\begin{abstract}
INTRODUCTION: SonicWeld Rx® system (KLS Martin) uses an ultrasonic sonotrode unit to bond a Resorb-X ${ }^{\circledR}$ pin to the Resorb-X® mesh and plates and underlying bone preclude the need to tap and decrease the time needed for fixation. Moreover, there is no second surgery needed for its removal.

OBJECTIVES: This study compared the use of resorbable mesh and plates with ultrasonic welded pins in management of mandibular fractures in children.

MATERIALS AND METHODS: This prospective comparative study was conducted on 20 children aged 6-12 years with mandibular fracture divided into 2 groups, group I was fixed with resorbable meshes and group II was fixed with resorbable plates. All patients were followed up clinically at the $2^{\text {nd }}, 7^{\text {th }}, 10^{\text {th }}$ and $14^{\text {th }}$ day postoperatively. Radiographically, all patients were examined by ultrasound(US) at $3,6,9$ months postoperatively and by cone beam computed tomography(CBCT) at 6 months.

RESULTS: Comparing the two groups clinically, there was no statistically significant difference at all stages of follow up. Radiographically, the difference in the mean thickness between the two groups was statistically insignificant at 3, 6, 9 months postoperatively. CBCT evaluation of bone density showed comparable results in both groups.

CONCLUSIONS: The SonicWeld Rx ${ }^{\circledR}$ system either the mesh or the plate were found to be satisfactory in the treatment of pediatric mandibular fractures, however proper case selection is essential criteria to make them successful. Ultrasonographic aid has proved an essential diagnostic aid in assessing the biodegradation process of the resorbable material over a period of 9 months in the present study.

KEYWORDS: resorbable material, SonicWeld Rx ${ }^{\circledR}$ system, pediatric mandibular fractures, ultrasound imaging

1- Assistant lecturer at the oral and maxillofacial department, Faculty of dentistry, Alexandria university, Alexandria, Egypt

2- Professor of Oral and Maxillofacial surgery, Faculty of dentistry, Alexandria university, Alexandria, Egypt

3- Professor of Radiodiagnosis, Department of Radiodiagnosis, Faculty of Medicine, Alexandria University, Alexandria, Egypt
\end{abstract}

\section{INTRODUCTION}

Fractures of the pediatric mandible are complicated by the anatomic complexity of the developing mandible, particularly by the presence of tooth buds and the eruption of deciduous and permanent teeth, that can occupy the entire vertical dimension of the bone and places teeth and the inferior alveolar nerve at risk during screw insertion (1). In addition, the ongoing development of the mandible poses risk of intrabony translocation of metal plates and screws, risking potential growth and teeth disturbances and difficulty with secondary removal if needed (2).

These led to the development of biodegradable hardware that was strong, biocompatible, adaptable, small, and provides enough stability to allow fracture healing and then resorb quickly without any foreign body reaction. Since their modulus of elasticity simulates bone, stress shielding effect is not a feature. Due to slow resorption, they transfer stresses slowly to bone preventing osteoporosis. These polymers can be broken down naturally by metabolic system. Bio-resorbable polymer science has evolved significantly in the last 20 years and each product is unique in terms of its polymer formulas, manufacturing technique, and handling characteristics, all of which influence strength and workability reference $(3,4)$.
The most relevant advantage of resorbable osteosynthesis systems is that there is no second-stage operation necessary to remove the material reference (5).

A new application system by welding a special configured Resorb-x ${ }^{\circledR}$ pin though ultrasound may overcome the disadvantages of thread tapping. With the advantage of only a 2 -step procedure, without cutting a thread into the bone the Resorb- $\mathrm{x}{ }^{\circledR}$ pin is welded in the corticospongy structure of the bone, using an ultrasonic tool. The Resorb- $\mathrm{x}{ }^{\circledR}$ mesh, plate and pins consist of an amorphous Poly D,L lactide (PDLLA) (6). The ultrasoundbased welding process allows the Resorb- $\mathrm{x}{ }^{\circledR}$ material to penetrate deeply into the bone structures, taking firm hold to generate a three-dimensional primary stability (7).

The hypothesis for this prospective evaluation was to compare the use of resorbable mesh and plates with ultrasonic welded pins in management of mandibular fractures in children. To prove this hypothesis, specific end points have been evaluated. The primary end point variables for this analysis were the stability and union of the fracture and return to normal function. Secondary end point variables included evaluation of the degree of edema, degree of pain, presence of infection, stability of fractured segment, occlusal disturbance, presence of abnormal sensation, and any other clinical findings. 


\section{MATERIALS AND METHODS}

This prospective comparative study was conducted on 20 children of both sexes suffering from mandibular fractures. They were selected from the Emergency Room of the InPatient Clinic of the Oral and Maxillofacial Surgery Department, Faculty of Dentistry, Alexandria University.

Ethical clearance and informed consent were obtained when patients met the inclusion criteria and their parents wished to participate in the study.

The patients were allocated randomly in to two groups each consisting of ten patients. In group I, the patients were treated with Resorb $x^{\circledR}$ meshes and Resorb $x^{\circledR}$ pin osteosynthesis. In group II, the patients were treated with Resorb $x ®$ plates and Resorb $x{ }^{\circledR}$ pin osteosynthesis. The inclusion criteria: 1) presence of unilateral or bilateral mandibular fractures 2) age ranged from 6-12 years old 3) fractures that required open reduction and fixation.

\section{Materials:}

Resorb $x^{\circledR}$ polymers (KLS Martin SonicWeld Rx, FDA approval 510(k) Number K121606, Gebruder Martin Gmbh \& Co. KG. Ludwigstaler Str.132. D-78532-Tuttlingen. Germany. www.klsmartin.com) consists of non-crystalline PDLLA, D-lactide and L-lactide (each 50\%) that is $100 \%$ amorphous. For group I, a multitude of different mesh forms and designs (1 $\mathrm{mm}$ thickness) give users a maximum of application flexibility. For group II, plates of $1 \mathrm{~mm}$ thickness and variable lengths were used according to each case.

Resorb $x{ }^{\circledR}$ pins of diameters 1.6 or $2.1 \mathrm{~mm}$ and 4,5 or 7 $\mathrm{mm}$ length was used according to each case. They were selfretaining by friction-fit. They were picked up with the sonotrode tip and were placed with no twisting motion in to the predrilled hole.

Xcelsior water bath (thermal unit) was used for the easy contouring of the resorbable material to be adapted to bone surface curvatures.

All patients were preoperatively evaluated both clinically and radiographically.

\section{Clinical examination:}

All children were subjected to full clinical examination by inspection and palpation of the fracture sites both extraorally and intra-orally to detect the presence of soft tissue laceration, hemorrhage, site of fracture, dentition, dearrangement of occlusion, areas of tenderness, step deformities, mobility of fractured segments, limitation of jaw movement, and damage to the teeth in or around the fracture line. In addition, nerve function, and the presence of associated injuries.

\section{Radiographic examination:}

Radiographic examination was accomplished for all patients at the time of presentation. Axial, coronal, 3D reconstruction computerized tomographies $(\mathrm{CT})$ were taken for all patients and any other necessary view if required according to each case.

These radiographic films are used to verify:

- The site of fracture.

- Displacement of fracture.

- Approximation of tooth buds to the fracture site.

\section{Surgical technique:}

All patients of this study were treated by open reduction and fixation under general anesthesia. All patients received intravenous antibiotic $750 \mathrm{mg}$ ampicillin sodium/sulbactam sodium 750mg (Unasyn 750, Pfizer) intraoperatively. The appropriate surgical approach was used according to each case. The patient's occlusion was checked and placed in to maximum intercuspation with intermaxillary fixation using eyelet wiring. After proper fracture reduction, fixation was done.

In group I, $1 \mathrm{~mm}$ thick resorbable mesh with ultrasound activated pins were placed. Rectangular and square meshes were used. The mesh was cut into smaller segments to fit the required location. The mesh was curved to include the contour of the lower border of the mandible if applicable (fig 1 a, b).

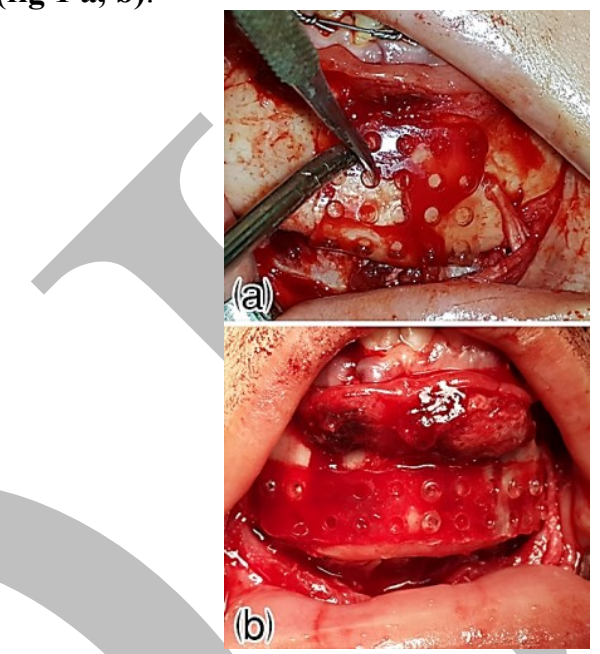

Figure (1): (a, b): Group I cases. a: square mesh, b: rectangular mesh after fixation.

In group II, $1 \mathrm{~mm}$ thick resorbable plate/plates with ultrasound activated pin were applied (fig 2 a, b). Plates of 4 holes or 8 holes were used. The plates were placed as is, provided that at least 2 screws were in the proximal and distal segments.

The ultrasonic unit of the SonicWeld $\mathrm{Rx}{ }^{\circledR}$ system was set to Level 2(capacity $20 \mathrm{~W}$ ). The resorbable material was dipped into the hot water bath for a few seconds to increase its pliability and then was adapted to the bone. The resorbable material hardened in seconds therefore the heating process was repeated for any portion of the resorbable material until satisfied with the contour. Final shaping was accomplished in situ by manual manipulation of the resorbable material while a small amount of warm saline flows over it. Next, the pilot hole (diameter 1.5 or 2 $\mathrm{mm}$ ) was predrilled using the SonicWeld $\mathrm{Rx}{ }^{\circledR}$ twist drill.

In group I, drill holes also included the contour of the lower border of the mandible.

In group II, drill holes were on the lower border of the mandible but not involving the contour of the lower border. A Sonic Pin $\mathrm{Rx}{ }^{\circledR}$ (diameter 1.6, $2.1 \mathrm{~mm}$, length 4, 5, $7 \mathrm{~mm}$ ) was secured on the sonotrode tip and seated it into the top of the pilot hole. Slight pressure was applied and maintained until the head is secured in the hole. At a minimum, 2 screws were placed on each side of the fracture. The surgical wound was closed in layers using vicryl suture material. Intermaxillary fixation and eyelet wiring were released and occlusion was verified. Finally, the stability of the osteosynthesis was tested clinically by applying slight pressure to the fragments. The sutures were removed after 7 to 10 days.

\section{Intraoperative evaluation}

- Failure rate of ultrasonic welded pins for all patients was assessed. 
- Stability of the resorbable mesh and plate after welding of the pins was recorded as stable if no mobility is present and unstable if mobility of the plate is present.

- Any difficulty of handling was recorded for all cases.

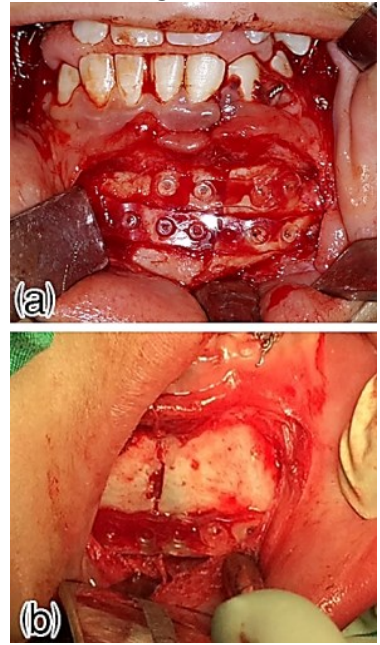

Figure (2): (a, b): Group II cases. a: a case where 2 plates were placed. b: a case where only 1 plate could be placed.

Postoperative care and follow-up assessment:

Antibiotic schedule was continued post-operatively for 72 hours using Amoxicillin trihydrate, Potassium clavulanate $625 \mathrm{mg}$ every 12 hours (Augmentin 625, GlaxoSmithKline) with an average dose of $50 \mathrm{mg} / \mathrm{kg}$ body weight in addition to anti-inflammatory drugs Ibuprofen 400mg (Brufen 400, Abbott). The doses were calculated and administered according to the age of each patient. The patients were instructed to follow soft diet for 4 weeks.

\section{A- Clinical evaluation:}

All cases were examined on the 2nd, 7th, 10th and 14th day postoperatively to evaluate the degree of pain through visual analogue scale (8), degree of edema by a tape measuring method (9), presence of infection. The stability of fractured segment was evaluated by gentle manual manipulation at the fractured site, the occlusal disturbance through proper occlusal relationship including molar relation and midline centralization, presence of abnormal sensation, and any other clinical findings.

\section{B- Radiographic evaluation}

Immediate post-operative orthopantomogram was done for all patients to confirm the proper reduction of the fracture line as well as the absence of any displacement of the fractured segment.

The patients were examined by ultrasound (Hitachi medical corporation 4-14-1, Soto Kanda, Chiyoda-Ku, Tokyo 101-0021, Japan) to evaluate the degradation process of the resorbable mesh and plate. Imaging was done at a period of 3, 6, 9 months postoperatively.

All patients were radiographically examined by cone beam computerized tomography (CBCT) (Veraviewepocs 3D R100 (J. Morita Inc. Japan) at a period of 6 months postoperatively using $\mathrm{CBCT}$ to evaluate healing at fracture line. Densometery was done to evaluate bone density.

Intraobserver reliability was done for the bone density and ultrasound measurements. Each measurement was repeated by the same specialist to check the repeatability of the measurements.

The results obtained from the study were compared using the appropriate statistical analysis. Wilcoxon signed ranks test, Mann Whitney test, $\chi^{2}$ : Chi square test, MC: Monte
Carlo for Chi square test, FE: Fisher Exact for Chi square test were used for the clinical results. Significance between ultrasound periods was done using Post Hoc Test (LSD) for ANOVA with repeated measures. Student t-test was used for comparing the mean density of the CBCT.

\section{RESULTS \\ Group I}

Included 10 patients; (eight males and two females). One patients had bilateral parasymphyseal fracture, two had right parasymphyseal fracture, three patients had left paraymphyseal, two had right mandibular body fracture and two had left body fracture. All patients were treated with Resorb $x \circledR$ meshes and Resorb $x{ }^{\circledR}$ pin osteosynthesis.

\section{Group II}

Included 10 patients; seven males and three females. Three had right parasymphyseal fracture, four patients had left paraymphyseal, two had left left body fracture and one had right body. All patients were treated with Resorb $x^{\circledR}$ plates and Resorb $x \circledR$ pin osteosynthesis.

Evaluation of the system intraoperatively:

A. Evaluation of ultrasonic welded pins: All pins were successfully handled and fixed with no incidence of fracture.

B. Stability of the resorbable mesh and plate after welding of the pins: In both groups all of the meshes and plates showed stability after welding.

C. The difficulty of handling: There was some difficulty of handling only in the early phase of the study but as experience was gained the handling was greatly improved and less time was needed throughout the operations for both groups.

\section{Evaluation of the system postoperatively:}

\section{- Clinical results:}

The results of this study showed that the post-operative clinical manifestation like pain and edema resolved within the normal range of time in both groups and the findings were comparable between the two groups and were within reasonable limits. Both groups showed no infection except only one patient $(10 \%)$ in group I (mesh). This patient had soft tissue infection due to poor oral hygiene which was managed conservatively with antibiotics. This patient showed good clinical results in the other clinical aspects.

In group I (mesh), 90\% of the patients had adequate stability while only $10 \%$ had inadequate stability that was stabilized by interdental wiring and continued without any complication by the 4 th postoperative week. In group II (plate), $70 \%$ of the patients had adequate stability while $30 \%$ of patients had inadequate stability although intraoperatively they showed adequate stability. Two of these patients were stabilized by interdental wiring and continued without any complication by the $4^{\text {th }}$ postoperative week. The third required MMF placement and had good stability after removal of MMF four weeks later.

In group I, $80 \%$ of the patients had good occlusion and $20 \%$ patients had satisfactory occlusion. In group II, $70 \%$ of the patients had good occlusion, $20 \%$ patients had satisfactory occlusion and only one patient $10 \%$ had mild occlusal derrangment. However, the patients were observed weekly without additional intervention and by the 4th postoperative week, the patient showed satisfactory occlusion. 
There was no incidence of iatrogenic post-operative sensory disturbance in both groups. All patients continued the follow up period without any abnormal sensation.

\section{- Radiographic results:}

Post-operative panoramic radiograph was taken within the first two days. In group I all patients $(n=10)$ showed good reduction and alignment of the osseous border of the mandible. In group II patients $(n=8)$ showed good reduction and alignment of the osseous border of the mandible and 2 patients showed mild disturbance of the inferior border.

Ultrasound imaging was conducted to evaluate the degradation process of the resorbable mesh and plate through measuring the thickness of the mesh and plate in millimeters from the outer hyperdense borders. Imaging was done at a period of 3, 6, 9 months postoperatively (fig $3 \mathbf{a}, \mathbf{b}, \mathbf{c})$. It was found that the thickness of the 50: 50 PDLLA resorbable material was stable $(1 \mathrm{~mm})$ for 3 months with a mean of $1.0 \pm 0.0$ in both groups. This was followed by a statistically insignificant increase from 3 months to 6 months with a mean of $1.04 \pm 0.07$ for group I and a mean of $1.02 \pm 0.04$ for group II. Following this, there was a statistically significant increase in thickness from 6 to 9 months with a mean of $1.12 \pm 0.06$ for group I was and 1.09 \pm 0.07 for group II. (Table $\mathbf{1}, \mathbf{2}$, fig 4) The difference in the mean thickness between the two groups was statistically insignificant at 3, 6, 9 months postoperatively.

Table (1): Comparison between the studied periods according to thickness of the resorbable material in group I.

\begin{tabular}{|c|c|c|c|}
\hline \multirow{2}{*}{ Cases No } & \multicolumn{3}{|c|}{ Thickness } \\
\cline { 2 - 4 } & $\mathbf{3}$ months & 6 months & 9 months \\
\hline $\mathbf{1}$ & 1 & 1.1 & 1.2 \\
\hline $\mathbf{2}$ & 1 & 1 & 1.1 \\
\hline $\mathbf{3}$ & 1 & 1 & 1 \\
\hline $\mathbf{5}$ & 1 & 1 & 1.1 \\
\hline $\mathbf{6}$ & 1 & 1.1 & 1.1 \\
\hline $\mathbf{7}$ & 1 & 1 & 1.1 \\
\hline $\mathbf{8}$ & 1 & 1 & 1.1 \\
\hline $\mathbf{9}$ & 1 & 1 & 1.2 \\
\hline $\mathbf{1 0}$ & 1 & 1.2 & 1.1 \\
\hline $\begin{array}{l}\text { Min. - Max. } \\
\text { Mean } \pm \text { SD. } \\
\text { Median }\end{array}$ & $1.0-1.0$ & $1.0-1.20$ & $1.0-1.20$ \\
\hline $\begin{array}{c}\text { Sig. bet. } \\
\text { periods }\end{array}$ & \multicolumn{3}{|c|}{$\mathrm{p}_{1}=0.104, \mathrm{p}_{2}<0.001^{*}, \mathrm{p}_{3}=0.003^{*}$} \\
\hline
\end{tabular}

Sig. bet. periods were done using Post Hoc Test (LSD) for ANOVA with repeated measures

$\mathrm{p}_{1}$ : $\mathrm{p}$ value for comparing between 3 months and 6 months $\mathrm{p}_{2}$ : $\mathrm{p}$ value for comparing between 3 months and 9 months $\mathrm{p}_{3}$ : $\mathrm{p}$ value for comparing between 6 months and 9 months

CBCT at 6 months postoperatively showed good alignment of the fractured segments without displacements. Bone density was measured in the vicinity of the fracture line using the cone beam CBCT software. Six readings were taken then their average was calculated to determine the mean bone density. The measurements were produced in Hounsfield units derived by the system software (fig 5). Both groups showed good healing. Mean bone density for group I was $1086.50 \pm 169.24 \mathrm{HU}$ and for group II was $1094.74 \pm 165.11$ HU. The difference in the mean bone density between the two groups was statistically insignificant $(p$ value $=0.913)$. $($ Table 3, fig 6)
Table (2): Comparison between the studied periods according to thickness of the resorbable material in group II.

\begin{tabular}{|c|c|c|c|}
\hline \multirow{2}{*}{ Cases No } & \multicolumn{3}{|c|}{ Thickness } \\
\cline { 2 - 4 } & $\mathbf{3}$ months & 6 months & 9 months \\
\hline $\mathbf{1}$ & 1 & 1 & 1.1 \\
\hline $\mathbf{2}$ & 1 & 1 & 1.2 \\
\hline $\mathbf{3}$ & 1 & 1 & 1.1 \\
\hline $\mathbf{4}$ & 1 & 1.1 & 1.1 \\
\hline $\mathbf{5}$ & 1 & 1 & 1.1 \\
\hline $\mathbf{6}$ & 1 & 1 & 1 \\
\hline $\mathbf{8}$ & 1 & 1 & 1.1 \\
\hline $\mathbf{9}$ & 1 & 1 & 1 \\
\hline $\mathbf{1 0}$ & 1 & 1.1 & 1.2 \\
\hline $\begin{array}{l}\text { Min. - Max. } \\
\text { Mean } \pm \text { SD. } \\
\text { Median }\end{array}$ & $1.0-1.0$ & $1.0-1.10$ & $1.0-1.20$ \\
\hline $\begin{array}{c}\text { Sig. bet. } \\
\text { periods }\end{array}$ & 1.0 & $1.02 \pm 0.04$ & $1.09 \pm 0.07$ \\
\hline \multicolumn{4}{|c|}{$\mathrm{p}_{1}=0.168, \mathrm{p}_{2}=0.004^{*}, \mathrm{p}_{3}=0.010^{*}$} \\
\hline
\end{tabular}

Sig. bet. periods were done using Post Hoc Test (LSD) for ANOVA with repeated measures

$\mathrm{p}_{1}$ : $\mathrm{p}$ value for comparing between 3 months and 6 months p2: $p$ value for comparing between 3 months and 9 months $\mathrm{p}_{3}$ : $\mathrm{p}$ value for comparing between 6 months and 9 months
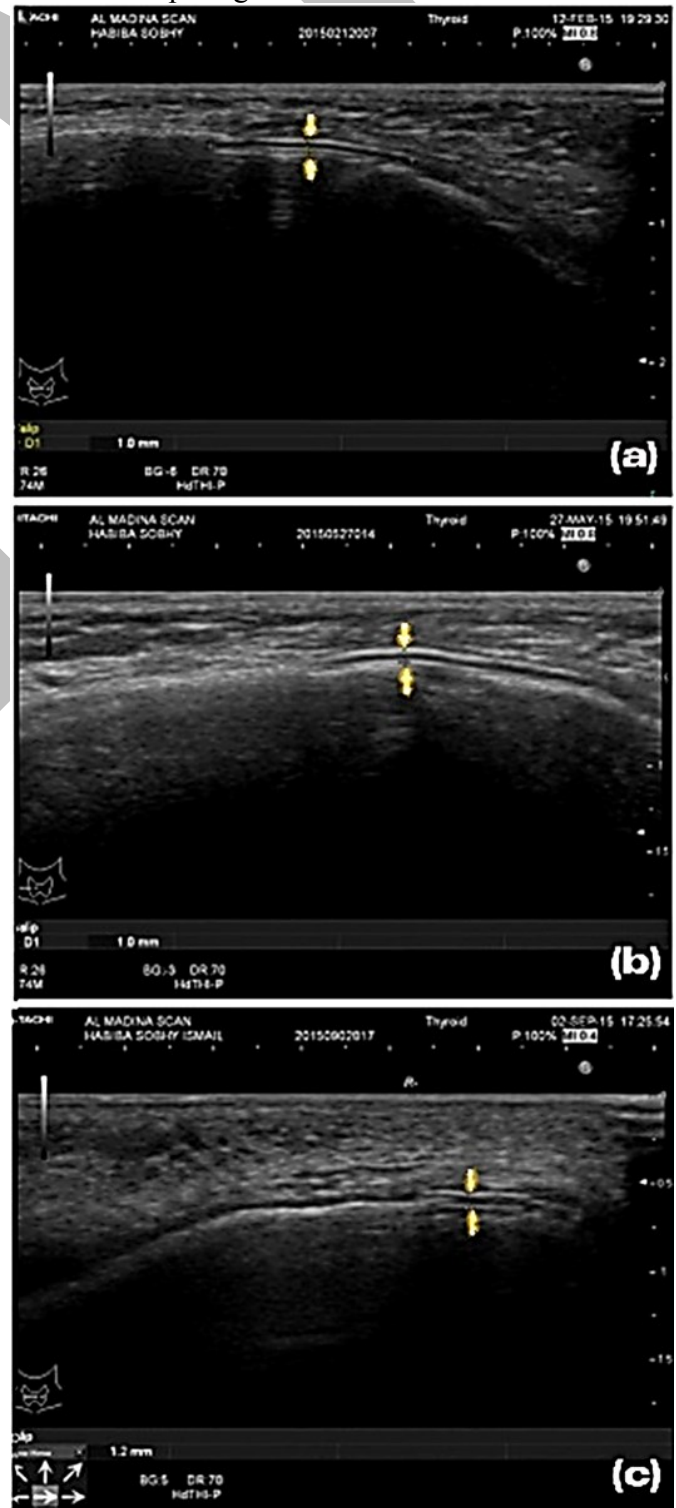

Figure (3): $(\mathbf{a}, \mathbf{b}, \mathbf{c})$ : Measurement of the resorbable material thickness by ultrasound for both groups. a: The thickness at 3 months remained the same $\mathrm{b}$ : The thickness at 6 months remained nearly the same c: The thickness at 9 months increased. 


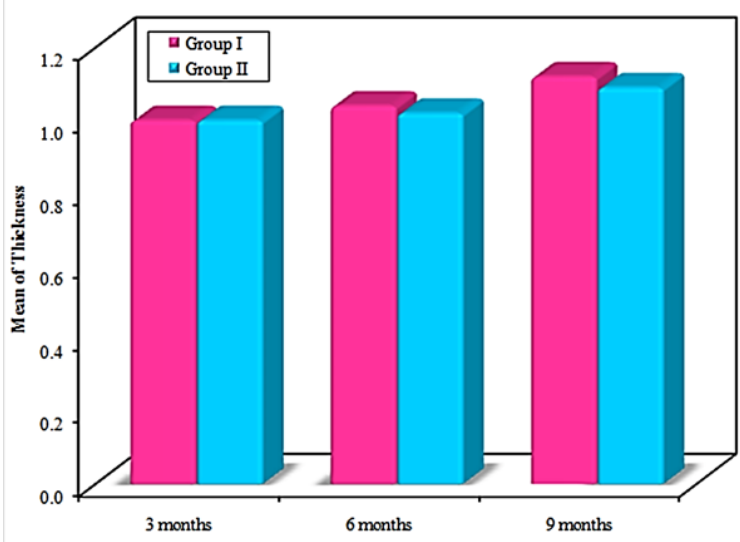

Figure (4): Comparison between the studied groups according to thickness of the resorbable material.

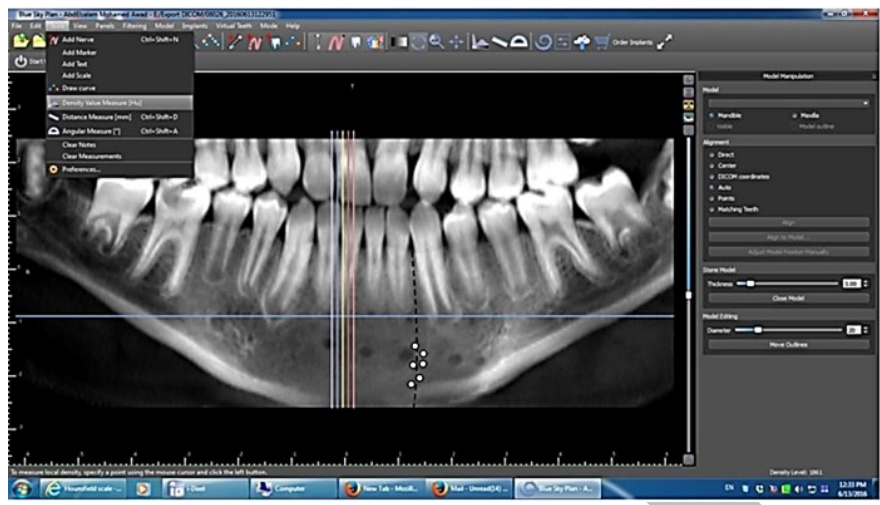

Figure (5): Bone density evaluation by $\mathrm{CBCT}$.

Table (3): Comparison between the studied groups according to the bone density at 6 months post operatively.

\begin{tabular}{|c|c|c|}
\hline \multirow{2}{*}{ Cases No } & \multicolumn{2}{|c|}{ Bone Density } \\
\hline $\mathbf{1}$ & Group I & Group II \\
\hline $\mathbf{2}$ & 1205 & 759 \\
\hline $\mathbf{3}$ & 805 & 1064 \\
\hline $\mathbf{4}$ & 1041 & 991 \\
\hline $\mathbf{5}$ & 1096 & 975 \\
\hline $\mathbf{6}$ & 751 & 872 \\
\hline $\mathbf{7}$ & 812 & 928 \\
\hline $\mathbf{8}$ & 910 & 853 \\
\hline $\mathbf{9}$ & 724 & 710 \\
\hline $\mathbf{1 0}$ & 943 & 825 \\
\hline Min. - Max. & $724-1205$ & 1002 \\
Mean \pm SD. & $910.0 \pm 159.79$ & $710-1064$ \\
Median & 861.50 & $897.90 \pm 113.80$ \\
\hline $\mathbf{2}$ (p) & \multicolumn{2}{|c|}{$0.195(0.848)$} \\
\hline
\end{tabular}

$t, p: t$ and $p$ values of Student t-test

\section{DISCUSSION}

A completely new approach, the SonicWeld system developed by KLS-Martin (Tuttlingen, Germany) in which the PDLLA resorbable osteosynthesis materials are fixed by inserting resorbable pins with the aid of ultrasonic sonotrode was used in this study for fixation of pediatric mandibular fractures.

Resorbable fixation system has the property of selfremoval after a period of time is an excellent alternative among pediatric patient group. Complete resorption of the plates and screws at the fracture site by biodegradation let the maxillofacial bones continue their physiological growing. These systems were reported to be reliable for mandibular fractures $(10,11)$.

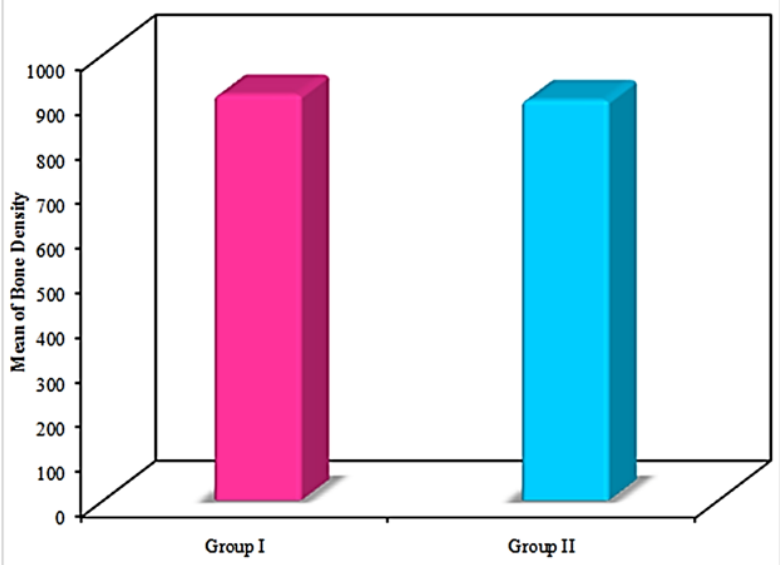

Figure (6): Comparison between the studied groups according to the bone density at 6 months post operatively.

The copolymer PDLLA has adequate mechanical strength and a shorter resorption than pure Poly-L lactide (PLLA) which requires a time of 5 years to resorb. This was in accordance with Suuronen et al 1999 (12), who determined that the copolymer PDLLA is especially recommended for children because of fast resorption and less risk of growth impairment for the fast growing skeleton.

This comparative study was conducted on 20 children with mandibular fracture. Fixation was done using the SonicWeld PDLLA meshes and plates.

In group I (mesh), either a square mesh or a rectangular mesh was used in each case. In group II (plates), 6 patients received two plates and 4 patients had only one plate. The inability to use 2 plates for all the patients in group II was due the fear of causing damage to the numerous teeth buds seen on the preoperative panorama.

Although Eppley 2005 (2) and Koltai et al 1995 (13) stated that the main advantage of resorbable screws in the pediatric mandible is the avoidance of potential injury to tooth buds, since the drill hole and tapping of the screw threads penetrate only the outer cortex. Therefore, injury to developing teeth is unlikely, even if the resorbable screw tip encroaches upon a tooth since the tip is blunt and none penetrating. Moreover, the subsequent resorption of the screws removes any potential obstruction to tooth eruption. However, in this study it was decided to take precaution to avoid any potential injury that could be caused during drilling specially when using the $7 \mathrm{~mm}$ pins.

In the patients where 2 plates were placed, the distance between the plates was deficient due to the narrow area of fixation, this was in accordance with El-saddany et al 2015 (14) stating that the size of the Resorb x plate did not give the opportunity for having adequate space between the plates when using more than one plate in the pediatric mandible.

Surgical efficiency with Sonic weld technique was enhanced and it may be the greatest advantage of this resorbable system over the conventional resorbable screws. Since the conventional resorbable screws need to be tapped with a separate instrument before insertion. This extra step increases operative time and can make placing the screw at an angle difficult because it is quite sensitive and can be easily fractured. Cheung et al 2004 (15) also reported an almost 5\% incident of screw fracture during placement. However, the application of pins with the ultrasonic welder eliminates the need to tap the drill hole, and the pins can be 
placed into drill holes at various angles without concern of fracture. In addition, Eckelt et al 2007 (16) stated that since the sonic weld pins were not exposed to torsional forces, the material did not fracture.

Recently, Pilling et al 2007 (17) demonstrated that the technique of "welding" a resorbable miniplate to bone with pins results in superior strength over using conventional resorbable screws with resorbable miniplates. This concept was further supported by Buijs et al 2009 (18) because they noted 11.5 times higher mean values for tensile strength, stiffness, and side bending with the SonicWeld Rx system versus the conventional Resorb-X alone without ultrasound energy. Further, resorbable plate in vitro strength analysis has shown similar characteristics to titanium plates (19). Also, Eckelt et al 2007 (16) used 1mm thick resorbable mesh in cranioplasty for infants and excellent stability was observed intraoperatively

As the energy is applied to the pin, it liquefies and becomes welded to the mesh or plate and penetrates into the neighboring bony structure. The SonicWeld Rx produces a maximum temperature of $33.1^{\circ} \mathrm{C} 1.0 \mathrm{~mm}$ from the implant, which dissipates quickly after ultrasonic energy is discontinued (20).

Pilling et al 2007 (17) demonstrated with an in vivo sheep model that overall mechanical stability of the ultrasound welded pin osteosynthesis was superior to conventional resorbable screw osteosynthesis.

A major advantage of using the resorbable material was that a second operation for plate removal was not required. This was in concurrence with Eckelt et al 2007 (16), and Degala et al 2013 (21).

The results of this study showed that the post-operative clinical manifestation like pain and edema resolved within the normal range of time in both groups and the findings were comparable between the two groups and were within reasonable limits.

The soft tissue infection due to poor oral hygiene was managed conservatively with antibiotics and showed improvement due to proper follow up of instructions. This agrees with the study by Degala et al 2013 (21) in which, soft tissue infection was seen postoperatively in 3 out of 13 patients $(23.1 \%)$ having mandibular fractures fixed with biodegradable plates. This occurred due to poor oral hygiene maintenance, and was managed conservatively with antibiotics. According to Cheung et al 2004(15), infection rates with resorbable materials have been shown to be from $1.4 \%$ to $10 \%$, including orthognathic and trauma cases. Trauma cases would be expected to be higher because of the increased incidence of contaminated wounds. Also, compared with metal plates, Park et al 2011 (22) demonstrated that resorbable fixation has similar complication rates in the treatment of maxillofacial fractures.

In group I (mesh), it was noticed that the instability was mostly due to improper follow up of the instructions by early introduction of solid food to the patients. The inadequate stability in group II (plate) was generally due the tension force on the upper border of the fracture that could not be sustained by a single plate on the lower border. Therefore, for these patients single jaw fixation using arch bars or interdental wiring was applied to the mandibular teeth for its tension band effect. Stability was achieved without any complication by the 4th postoperative week. This technique was advocated by other authors for use in pediatric patients (23-25). Also, Kallela et al 1998 (26) observed good stability after mandibular advancement and fixation with polylactide biodegradable screws. Singh et al 2012 (27) found significant stability of fracture fragments on different follow ups when evaluated the efficacy of bioresorbable plates in pediatric mandibular fracture. Degala et al 2013 (21) fixed zygomatic and mandibular fractures with biodegradable plates and concluded that the stability of the fractured fragments and handling characteristics of the bioresorbable system were comparable with the metal system

In this study, it was believed that in group I, the mesh had a large contact surface area with the bone. Therefore, it would be reasonable to assume that the resorbable mesh used in group I may have superior fixation properties over the resorbable miniplates used in group II regarding rigid fixation. This was in agreement with Cho et al 2011 (28) who discussed that the mesh provided an increased surface area contact to the bone and is stabilized in multiple locations with the welded pins, and even in thin, tenuous bone, "a rivet like" retention can be achieved.

Regarding the malocclusion, the results were similar to a study conducted by Bhatt et al 2010 (29) in which 11\% malocclusion was seen in resorbable group, i.e., in two patients.

None of the patients complained of preoperative sensory disturbance nor iatrogenic post-operative sensory disturbance in both groups. This disagrees with Degala et al 2013 (21), who fixed zygomatic and mandibular fractures with biodegradable plates noted temporary paresthesia in three patients out of thirteen $(23.1 \%)$ both preoperatively and postoperatively. The paresthesia improved over 8 weeks in two patients and over 2 weeks in another patient. The other ten patients $(76.9 \%)$ had no neurosensory changes. Another study by Singh et al 2012 (27) on 40 pediatric mandibular fractures fixed by resorbable plates, found paraesthesia in two patients with body fracture which remained for 2 week and 1 month follow-up. No paraesthesia was found after 3rd follow-up.

Ultrasound imaging was valuable for evaluation the degradation process of the resorbable mesh and plate. This confirms with Hiedmann and Gerlach 2002 (30), where ultrasound imaging of the polylactide osteosynthesis material was possible, the thickness of the osteosynthesis plates was easily measured and the process of degradation could be easily documented.

The results of this study showed that the significant increase in thickness in both groups was observed at 9 months. This agrees with Hiedmann and Gerlach 2002 (30) in which the thickness of $50: 50$ PDLLA plates stayed stable for about 8 months (phase I), thereafter the water intake started (phase II) and the thickness increases, reaching the maximum (about $300 \%$ of the initial thickness) between 14 and 18 months (phase III). In the following period, a decrease of thickness of the polymer was measurable (Phase IV). The 50: 50 PDLLA osteosynthesis plates were not palpable or visible with ultrasound beyond 30 months' post-implantation.

CBCT has a relatively low cost as well as radiation dose as compared to conventional CT $(31,32)$. Conventionally, its software has the tools necessary for radiographic density calculation (31) It is a dependable method for measuring bone density. In this study the bone density values showed good healing in both groups. The insignificant difference in 
the mean bone density between the two groups indicated that the SonicWeld $\mathrm{Rx}{ }^{\circledR}$ system was adequate for healing and new bone formation to take place. This was in accordance with an experimental study by Kropil et al 2012 (33) who has proved that CBCT volumetry allows for reliable, noninvasive, quantitative monitoring of bone defect healing.

\section{CONCLUSIONS}

The SonicWeld $\mathrm{Rx}{ }^{\circledR}$ system either the mesh or the plate were found to be satisfactory in the treatment of pediatric mandibular fractures, however proper case selection is essential criteria to make them successful. Ultrasonographic aid has proved an essential diagnostic aid in assessing the biodegradation process of the resorbable material over a period of 9 months in the present study.

\section{CONFLICT OF INTEREST}

The authors declare that they have no conflict of interest.

\section{REFERENCES}

1. Smartt JM, Jr., Low DW, Bartlett SP. The pediatric mandible: II. Management of traumatic injury or fracture. Plast Reconstr Surg. 2005 Aug;116(2):28e-41e.

2. Eppley BL. Use of resorbable plates and screws in pediatric facial fractures. J Oral Maxillofac Surg. 2005;63(3):385-91.

3. Bell B, Kindsfater C. The use of biodegradable plates and screws to stabilize facial fractures. J Oral Maxillofac Surg 2006; 64:31-9.

4. Enislidis G, Pichorner S, Lambert F, Wagner A, Kainberger F, Kautzky Mea. Fixation of Zygomatic fractures with a new biodegradable copolymer osteosynthesis system. Preliminary results. Int J Oral Maxillofac Surg. 1998; 27:352-5.

5. Reichwein A, Schicho K, Moser D, Seemann R, Poeschl P, Baumann A, et al. Clinical experiences with resorbable ultrasonic-guided, angle-stable osteosynthesis in the panfacial region. J Oral Maxillofac Surg. 2009;67(6):1211 7.

6. Carron MA, Zuliani G, Pereira L, Abuhamdan M, Thibault A, Dau N, et al. Stability of midface fracture repair using absorbable plate and screw system pilot holes drilled and pin placement at angles other than 90 degrees. J Facial Plast Surg. 2014;16(1):42-8.

7. Burger BW. Use of ultrasound-activated resorbable Poly-DL-lactide pins (SonicPins) and foil panels (Resorb-X) for horizontal bone augmentation of the maxillary and mandibular alveolar ridges. J Oral Maxillofac Surg. 2010 Jul;68(7):1656-61.

8. Rosivack RG, Koenigsberg SR, Maxwell KC. An analysis of the effectiveness of two topical anesthetics. Anesth Prog. 1990;37(6):290-2.

9. Benetello V, Sakamoto FC, Giglio FPM, Sakai VT, Calvo $\mathrm{AM}$, Modena KCS, et al. The selective and non-selective cyclooxygenase inhibitors valdecoxib and piroxicam induce the same postoperative analgesia and control of trismus and swelling after lower third molar removal. Braz J Med Biol Res. 2007; 40:1133-40.

10. Yerit KC, Enislidis G, Schopper C, Turhani D, Wanschitz F, Wagner A, et al. Fixation of mandibular fractures with biodegradable plates and screws. Oral Surg Oral Med Oral Pathol Oral Radiol Endod. 2002;94(3):294-300.

11. Edwards RC, Kiely KD, Eppley BL. Fixation of bimaxillary osteotomies with resorbable plates and screws: experience in 20 consecutive cases. J Oral Maxillofac Surg. 2001 Mar;59(3):271-6.

12. Suuronen R, Haers PE, Lindqvist C, Sailer HF. Update on bioresorbable plates in maxillofacial surgery. Facial Plast Surg. 1999;15(1):61-72.

13. Koltai PJ, Rabkin D, Hoehn J. Rigid fixation of facial fractures in children. $\mathrm{J}$ Craniomaxillofac Trauma. 1995;1(2):32-42.

14. El-Saadany WH, Sadakah AA, Hussein MM, Saad KA. Evaluation of using ultrasound welding process of biodegradable plates for fixation of pediatric mandibular fractures. Tanta Dent J 2015; 12(Suppl 1): S22-S9.

15. Cheung LK, Chow LK, Chiu WK. A randomized controlled trial of resorbable versus titanium fixation for orthognathic surgery. Oral Surg Oral Med Oral Pathol Oral Radiol Endod. 2004;98(4):386-97.

16. Eckelt U, Nitsche M, Muller A, Pilling E, Pinzer T, Roesner D. Ultrasound aided pin fixation of biodegradable osteosynthetic materials in cranioplasty for infants with craniosynostosis. J Craniomaxillofac Surg. 2007;35(45):218-21.

17. Pilling E, Meissner H, Jung R, Koch R, Loukota R, Mai R, et al. An experimental study of the biomechanical stability of ultrasound-activated pinned (SonicWeld Rx+Resorb-X) and screwed fixed (Resorb-X) resorbable materials for osteosynthesis in the treatment of simulated craniosynostosis in sheep. Br J Oral Maxillofac Surg. 2007;45(6):451-6.

18. Buijs GJ, van der Houwen EB, Stegenga B, Verkerke GJ, Bos RR. Mechanical strength and stiffness of the biodegradable SonicWeld Rx osteofixation system. J Oral Maxillofac Surg. 2009 Apr;67(4):782-7.

19. Araujo MM, Waite PD, Lemons JE. Strength analysis of Le Fort I osteotomy fixation: titanium versus resorbable plates. J Oral Maxillofac Surg. 2001 Sep;59(9):1034-9; discussion $9-40$.

20. KLS Martin: SonicWeld Rx-A New Era in Resorbable Craniofacial Osteosynthesis. Jacksonville F, KLS Martin.

21. Degala S, Shetty S, Ramya S. Fixation of zygomatic and mandibular fractures with biodegradable plates. Ann Maxillofac Surg. 2013;3(1):25-30.

22. Park CH, Kim HS, Lee JH, Hong SM, Ko YG, Lee OJ. Resorbable skeletal fixation systems for treating maxillofacial bone fractures. Arch Otolaryngol Head Neck Surg. 2011;137(2):125-9.

23. Eldibany R, Khalil M. The use of resorbable osteosynthesis material for stabilization of mandibular fractures in children. 2005; 51:2133-41.

24. Hardt N, Gottsauner A. The treatment of mandibular fractures in children. J Craniomaxillofac Surg 1993; 21: 214-9.

25. Peltoniemi H, Tulamo R, Pihlajamaki HKea. Consolidation of craniotomy lines after resorbable polylactide and titanium plating: A comparative experimental study in sheep. Plast Reconstr Surg. 1998; 101:123-33.

26. Kallela I, Laine P, Suuronen R, Iizuka T, Pirinen S, Lindqvist C. Skeletal stability following mandibular advancement and rigid fixation with polylactide biodegradable screws. Int $\mathrm{J}$ Oral Maxillofac Surg. 1998;27(1):3-8.

27. Singh G, Mohammad S, Chak RK, Lepcha N, Singh N, Malkunje LR. Bio-Resorbable Plates as Effective Implant in Paediatric Mandibular Fracture. J Maxillofac Oral Surg. 2012;11(4):400-6. 
28. Cho PW, Burton RG, Gratton D, Cho JH. Biomechanical study of SonicWeld Rx pin in cortical bone graft layering technique. J Oral Maxillofac Surg. 2011;69(5):1519-24.

29. Bhatt K, Roychoudhury A, Bhutia O, Trikha A, Seith A, Pandey RM. Equivalence randomized controlled trial of bioresorbable versus titanium miniplates in treatment of mandibular fracture: a pilot study. J Oral Maxillofac Surg. 2010 Aug;68(8):1842-8.

30. Heidemann W, Gerlach KL. Imaging of biodegradable osteosynthesis materials by ultrasound. Dentomaxillofac Radiol. 2002;31(3):155-8.

31. Naitoh M, Katsumata A, Mitsuya S, Kamemoto H, Ariji E. Measurement of mandibles with microfocus $\mathrm{X}$-ray computerized tomography and compact computerized tomography for dental use. Int J Oral Maxillofac Implants. 2004;19(2):239-46.

32. White SC, Pharoah MJ. The evolution and application of dental maxillofacial imaging modalities. Dent Clin North Am. 2008;52(4):689-705.

33. Kropil P, Hakimi AR, Jungbluth P, Riegger C, Rubbert C, Miese F, et al. Cone beam CT in assessment of tibial bone defect healing: an animal study. Acad Radiol. 2012;19(3):320-5.

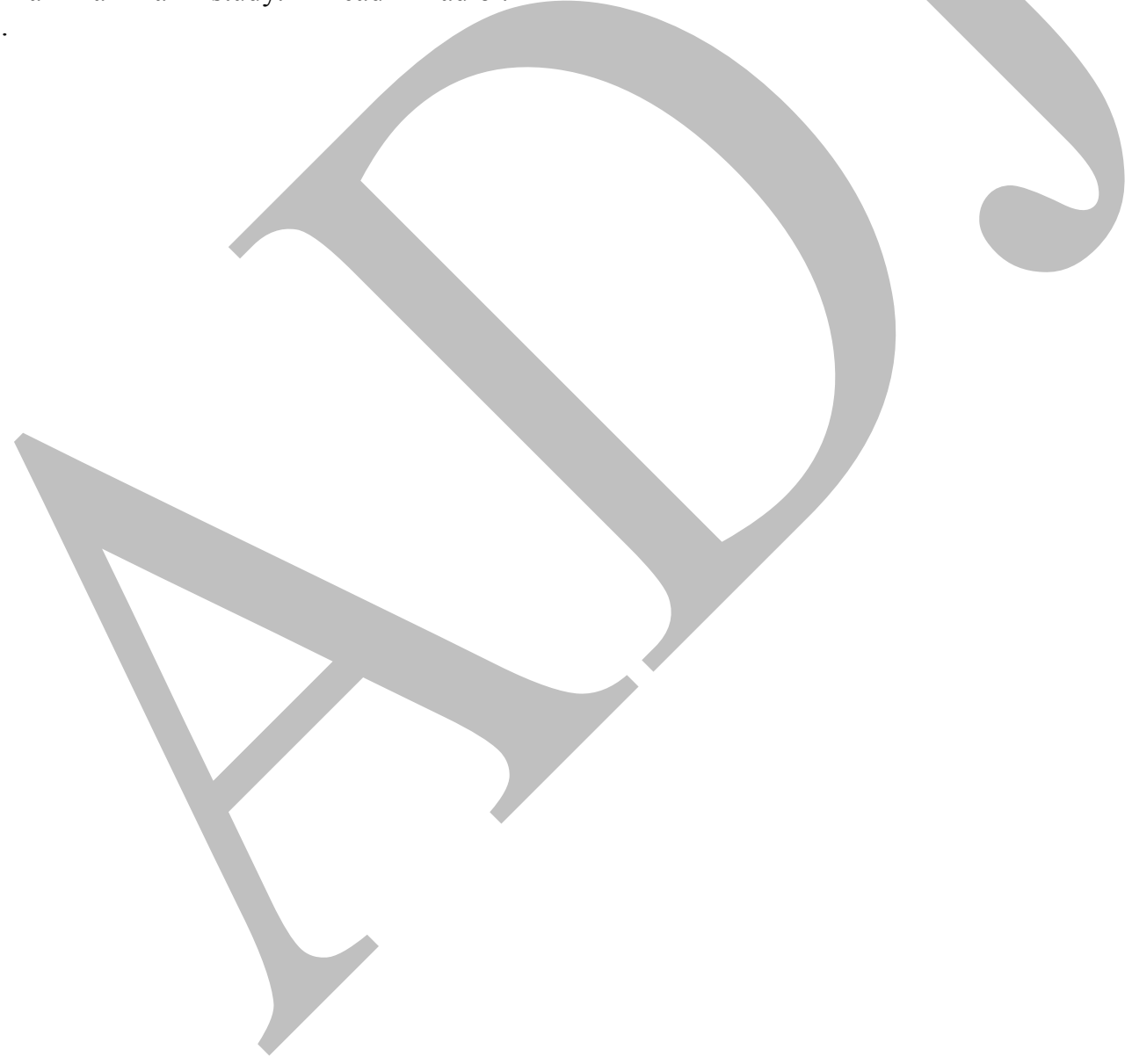

